\title{
Carotenoid accumulation in Dietzia maris NITD protects from macromolecular damage
}

\author{
SUROJIT BERA * \\ Department of Microbiology, School of Bioengineering and Biosciences, Lovely Professional University, Punjab, India
}

\begin{abstract}
Over the past decades, nutraceuticals have attracted considerable interest because of their potential nutritional, safety and therapeutic effects. Carotenoid molecules are potent nutraceuticals with an attractive colour and have been shown to play crucial roles in the immune system and susceptibility of organisms to certain diseases. Reactive oxygen species (ROS) are considered to be a major threat to cellular components and lead to protein oxidation, lipid peroxidation and DNA damage. In the present study, canthaxanthin (CX), an orange-red keto-carotenoid, was extracted from Dietzia maris NITD. Carbonyl content measurement showed that the presence of CX can prevent protein oxidation in $D$. maris NITD. The inhibition of protein oxidation in vitro revealed a high correlation coefficient of the extracted CX with positive controls. Both the linoleic acid model $\left(\mathrm{IC}_{50}=932.48 \mu \mathrm{g} / \mathrm{ml}\right)$ and the goat liver model experiments showed that CX can also inhibit lipid peroxidation in vitro. CX from $D$. maris NITD was also proved to be effective in maintaining the observable intactness of a model DNA (pBR322). The present study indicated that bacterial CX can be a useful bioactive compound to prevent oxidative damage incurred by cellular macromolecules in terms of pharmaceutical and nutraceutical aspects.
\end{abstract}

Key words: canthaxanthin, ROS, protein oxidation, nutraceutical, linoleic acid

\section{Introduction}

Cellular metabolism involves the formation of reactive oxygen species (ROS) in their routine metabolic pathways and defends their master cells from invading pathogens. ROS also play a key role in intracellular signalling pathways (Bera, 2019). However, the augmentation of ROS may sometimes lead to oxidative stress, and consequently, the protection provided by the antioxidant defence system may become ineffective (Simon et al., 2000). In such cases, different ROS, for example, hydrogen peroxide or hydrogen and superoxide radicals produced during respiration, might cause an oxidative injury to the building blocks of cells and tissues, i.e. proteins, lipids and nucleic acids (Simon et al., 2000). Cellular oxidation can interfere with the protein function as the unfolded proteins lead to an enhanced hydrophobicity and often result in the formation of toxic aggregates (Costa et al., 2007). Free radicals also cause oxidation of the cellular thiols, which eventually affects key enzymes and lipid peroxidation as well as leads to chromosomal aberrations (Kumar et al., 2013). Because of increased ROS levels, humans develop serious health conditions, including cancer, cardiovascular diseases, inflammatory conditions, diabetic complications, Alzheimer's disease, aging etc. (Sonar et al., 2016). For their survival, cells use enzymatic and non-enzymatic defence systems such as production of antioxidants (Simon et al., 2000). Synthetic antioxidants are presently becoming popular as nutritional supplements. However, possible side effects (e.g. cytotoxic and carcinogenic) of synthetic antioxidants have further increased the interest in searching for potential antioxidants of natural origin (Kumar et al., 2013). Hence, different bioactive molecules, e.g. polyphenols, unsaturated fatty acids, oligosaccharides etc., from natural sources have gained rapid popularity because of their strong radical scavenging activities (Mitra et al., 2016). In this regard, microorganisms are more suitable for the production of bioactive compounds be-

\footnotetext{
* Corresponding author: Department of Microbiology, School of Bioengineering and Biosciences, Lovely Professional University, Punjab, India-144411; e-mail: suromic@gmail.com
} 
cause they can give high yield independent of culture conditions as they can be grown in a laboratory on a variety of substrates (Mitra et al., 2017a).

Dietzia sp. (family Dietziaceae, suborder: Corynebacterineae, order: Actinomycetales) are gram-positive bacteria that have been isolated from various environments such as soil, sweet water ponds, and effluents from sugar industry (Venugopalan et al., 2013). Although the genus Dietzia appeared to be a promising hydrocarbon degrader in recent years (Gharibzahedi et al., 2014), some species such as Dietzia natronolimnaea HS-1 (Khodaiyan et al., 2007), Dietzia maris NITD (Goswami et al., 2012) and Dietzia spp. (Venugopalan et al., 2013) showed a significant ability to produce canthaxanthin (CX) as their secondary metabolite. CX is an orange-red ketocarotenoid with significant applications in food and feed industry owing to its strong antioxidant property and anticancer, anti-inflammatory and immunomodulatory activities (Mitra et al., 2018). D. maris NITD is a gram-positive, aerobic, non-motile bacterium that has been established as an efficient CX producer (Goswami et al., 2012). Carotenoids are receiving worldwide attention because of their strong antioxidant activity and attractive color. They have gained a strong place in biopharmaceutical and nutraceutical industries in addition to their use as food additives (Bera and Dutta, 2017; Mitra et al., 2017b).

In our previous work, CX from $D$. maris NITD (BCX) was shown to have high free radical scavenging activities in a purified form as measured by different antioxidant assays (Bera et al., 2015). In a follow-up study with different protective model systems, BCX was shown to have a high antioxidant activity after encapsulation in hydrogels (Bera and Dutta, 2017) or in a natural aqueous-based model system such as aloe vera (Bera et al., 2017). In addition to $\mathrm{CX}$ production ability, the bioremediation potential of $D$. maris NITD in terms of synthetic dye removal has also been reported recently (Bera et al., 2016). However, the effect of BCX on important cellular biomolecules (such as proteins, lipids or nucleic acids) in $D$. maris NITD has not yet been studied. In the present study, a non-carotenoid-producing strain $D$. maris 7011 was obtained to compare the protective mechanism of carotenoids in D. maris NITD (a carotenoid producer). Assays were performed to measure the levels of protein carbonylation and oxidation inhibition, and the results were compared with those of other standard carotenoids such as $\beta$-carotene, $\beta$-cryptoxanthin and zeaxanthin. The effect on lipid peroxidation was also analysed using the linoleic acid model (thiobarbituric acid reactive substances, TBARS) and the goat liver model. DNA damage prevention was determined by the DNA nicking assay by using the pBR322 plasmid DNA.

\section{Materials and methods}

\section{Chemicals, bacterial strains and growth conditions}

Media ingredients for bacterial cultivation were purchased from HiMedia, India. Chemicals for the protein oxidation assay, lipid peroxidation assay and DNA damage assay were purchased from Sigma-Aldrich (St. Louis, MO, USA). All solvents used in this study were HPLC grade (Sigma-Aldrich). The pBR322 plasmid DNA was purchased from Thermo Scientific, USA. Standard carotenoids were supplied by Sigma-Aldrich. $D$. maris NITD (accession number: HM151403) was previously isolated in our laboratory and was established as an effective CX producer (Bera and Dutta, 2017). Optimized medium (D-glucose: $15 \mathrm{~g}$, yeast extract: $5 \mathrm{~g}$, peptone: $10 \mathrm{~g}$, sodium chloride: $5 \mathrm{~g}$, distilled water: $1000 \mathrm{ml}$ ) supplemented with coconut water was used for a large-scale pigment production at the initial broth $\mathrm{pH}$ 6.7, $120 \mathrm{rpm}$ and $25^{\circ} \mathrm{C}$ (Bera et al., 2017). The pigment was extracted according to the procedure of Goswami et al. (2012). The extracted pigment was concentrated using a rotary evaporator (Yamato, model RE301) and was freeze-dried (Digitech, India). Dried BCX was stored at $4{ }^{\circ} \mathrm{C}$ for further experiments. D. maris 7011 was purchased from MTCC, Chandigarh, India, and maintained in a medium containing $30 \mathrm{~g}$ trypticase soy broth, $15 \mathrm{~g}$ agar and $1000 \mathrm{ml}$ distilled water.

\section{Measurement of protein carbonylation level}

Cells of $D$. maris NITD and $D$. maris 7011 in a suspension with an optical density (OD) of approximately $0.3-0.5$ at $600 \mathrm{~nm}$ were treated with $\mathrm{H}_{2} \mathrm{O}_{2}(30 \mathrm{mmol} / \mathrm{l})$. The cells were harvested and re-suspended in phosphate-buffered saline (PBS) containing 1\% v/v $\beta$-mercaptoethanol and $1 \mathrm{mmol} / 1 \mathrm{PMSF}$ (phenylmethylsulfonyl fluoride). To obtain a cell-free extract, the cells were sonicated and centrifuged (1000 $g$ for $10 \mathrm{~min}$ ). The protein concentration of the cell-free extract was determined (Bradford, 1976), and the proteins were diluted to $1 \mathrm{mg} / \mathrm{ml}$ of protein. The control protein was incubated 
with $200 \mu \mathrm{l}$ of $5 \mathrm{mmol} / \mathrm{l} \mathrm{DNPH}$ (2,4-dinitrophenylhydrazine) and $1 \mathrm{~mol} / \mathrm{l} \mathrm{HCl}$ for $1 \mathrm{~h}$ in the dark and vortexed at regular intervals. TCA (10\%, ice-cold) was used to precipitate the proteins which were washed 3 times with $50 \%$ ethyl acetate in ethanol to remove the excess DNPH. The decoloured precipitate was evaporated and dissolved in $1 \mathrm{ml}$ of $3 \mathrm{M}$ guanidine hydrochloride (Tian et al., 2009). The absorbance of the supernatant was measured at 370 $\mathrm{nm}$. The protein control used was processed in a similar manner, but DNPH was replaced with $1 \mathrm{M} \mathrm{HCl}$. The protein carbonyl content was expressed as $\mathrm{mmol} / \mathrm{mg}$ of protein.

\section{Assay of the inhibitory effect of carotenoids on protein oxidation in vitro}

To investigate the inhibitory effect of carotenoids in protein oxidative damage, bovine serum albumin (BSA) was used as the targeted protein. One millilitre of $1 \mathrm{mg} / \mathrm{ml} \mathrm{BSA}$ was mixed with $500 \mu \mathrm{l}$ of carotenoid samples (dissolved in tetrahydrofuran or THF) and then treated with $500 \mu \mathrm{l}$ of $1 \mathrm{mmol} / \mathrm{FeSO}_{4}$ and $500 \mu \mathrm{l}$ of $80 \mathrm{mmol} / 1 \mathrm{H}_{2} \mathrm{O}_{2}$ at $37^{\circ} \mathrm{C}$ for $1 \mathrm{~h}$. To stop the reaction process, catalase ( $30 \mathrm{U})$ was added. The obtained solution was incubated with $1 \mathrm{ml}$ of $10 \mathrm{mmol} / \mathrm{l} \mathrm{DNPH}$ for $1 \mathrm{~h}$ and then treated as mentioned earlier in the "Measurement of protein carbonylation level" section. The absorbance of the supernatant was determined at the wavelength of $370 \mathrm{~nm}$. The inhibition of protein oxidation (\%) by carotenoids was calculated using the following equation:

Inhibition of protein oxidation $[\%]=$

$$
=\frac{\left[\left(\mathrm{A}_{\text {control }}-\mathrm{A}_{\text {blank }}\right)-\left(\mathrm{A}_{\text {sample }}-\mathrm{A}_{\text {blank }}\right)\right]}{\left(\mathrm{A}_{\text {control }}-\mathrm{A}_{\text {blank }}\right)} \times 100
$$

where $A_{\text {control }}$ is the absorbance of the control, $A_{\text {blank }}$ is the absorbance of the background (using $\mathrm{H}_{2} \mathrm{O}$ replace $\mathrm{FeSO}_{4}$ and $\mathrm{H}_{2} \mathrm{O}_{2}$ and $\mathrm{A}_{\text {sample }}$ is the absorbance of the sample (Tian et al., 2009). Ascorbic acid and butylated hydroxyanisole (BHA) were used as positive controls. The data obtained were compared with the inhibitory efficiency of other standard carotenoids such as $\beta$-carotene, $\beta$-cryptoxanthin and zeaxanthin.

\section{Effect of carotenoids from D. maris NITD on lipid oxidation}

\section{Lipid oxidation study in the linoleic acid model}

The inhibition of lipid peroxidation by the carotenoid extract was studied in a linoleic acid emulsion model ac- cording to the method described by Lingnert et al. (1979) with some modifications. Briefly, an emulsion of linoleic acid was prepared with Tween 20 in $0.2 \mathrm{M}$ sodium phosphate buffer ( $\mathrm{pH}$ 7.2). Next, $20 \mathrm{mM}$ of the linoleic acid emulsion was prepared by dissolving linoleic acid in $5.0 \mathrm{ml}$ absolute methanol and adjusting the volume to $25 \mathrm{ml}$ with the addition of $0.2 \mathrm{M}$ sodium phosphate buffer ( $\mathrm{pH}$ 7.2). Five hundred microliters of each carotenoid extract (concentration range of $100-500 \mu \mathrm{g} / \mathrm{ml}$ ) in methanol was mixed with $2.0 \mathrm{ml}$ of linoleic acid emulsion and tested for antioxidant activity. $\mathrm{IC}_{(50)}$ values were determined. Ascorbic acid and BHA were used as positive controls.

\section{Lipid oxidation study in the goat liver model}

Lipid peroxidation inhibition by the carotenoid extract was studied in the goat liver model following the method of Kumar et al. (2013) with some modifications. In brief, a freshly excised goat liver (experiments were repeated 3 times) was collected in a sterile container and kept in an icebox till further use. Ten grams of the liver was homogenized in cold PBS of $\mathrm{pH}$ 7.4. The colloidal solution containing unbroken liver cells were subjected to sonication, and $10 \%$ homogenate was prepared. The obtained solutions were filtered and centrifuged to get clear supernatants. The entire process was performed ice. Varying concentrations $(100-500 \mu \mathrm{g} / \mathrm{ml})$ of the extract were added to $5 \mathrm{ml}$ liver homogenate, and lipid peroxidation was initiated by adding $250 \mu \mathrm{l}$ ferrous sulphate $(25 \mathrm{mM})$. After $30 \mathrm{~min}$ of incubation, $1 \mathrm{ml}$ aliquots were placed in tubes, and the proteins were precipitated using ice-cold 10\% TCA. The solutions were centrifuged, and the supernatants were mixed with $0.67 \%$ TBA in $50 \%$ acetic acid. The obtained mixtures were heated for $30 \mathrm{~min}$ in a boiling water bath, and the intensity of the pink complex was measured at $535 \mathrm{~nm}$. The degree of lipid peroxidation was assayed by estimating the TBARS content, and the results were expressed as a percentage of inhibition (Tan et al., 2014). Ascorbic acid and BHA were used as positive controls.

\section{DNA damage protection activity}

To test the effects of carotenoids from $D$. maris NITD on DNA (pBR322) damage, the reaction was conducted in a sterile tube. DNA damage was induced by free hydroxyl radicals generated by Fenton's reagent (Tian et al., 2007). Briefly, $1 \mu$ of DNA was suspended in $2.5 \mu \mathrm{l}$ PBS (50 mmol, $\mathrm{pH} 7.4$ ) and $3.5 \mu \mathrm{l} \mathrm{FeSO}_{4}$ 
$(2 \mathrm{mM})$. Next, $2.5 \mu \mathrm{l}$ of the carotenoid extract was mixed in varied concentrations with the solution, and $4.5 \mu \mathrm{l}$ $\mathrm{H}_{2} \mathrm{O}_{2}$ was added to start radical generation. The mixture was incubated at $37^{\circ} \mathrm{C}$ for $30 \mathrm{~min}$. The mixture was then subjected to 0.8\% agarose gel electrophoresis using $\mathrm{EtBr}$ staining. Quercetin was used as a positive control.

\section{Statistical analysis}

All experiments were performed in triplicates. The results were expressed as mean \pm standard deviation (SD) of their values. An analysis of variance (ANOVA) was performed followed by Tukey's test using SPSS 16 software (SPSS Inc., Chicago, USA). A value of $P<0.05$ was considered significant.

\section{Results and discussion}

\section{Effect of carotenoids from D. maris NITD on protein oxidation}

Oxidative stress may lead to cell injury, which is evident from the measurement of biochemical markers of protein oxidation. Protein carbonyls (PCOs) are the common by-products of protein oxidation, and their quantification can be used to measure the extent of oxidative modification (Rajendran et al., 2012). Carotenoids react with free radicals through an additional reaction at their conjugated double bonds, resulting in the formation of relatively stable products (Tian et al., 2009). Proteins are the major components of the cells and are highly susceptible to post-translational modifications due to radiation and free radicals; thus, the degree of cell resistance may be determined by the level of oxidative protein damage (Daly et al., 2007).

The carbonyl content may have a role as a biomarker for detecting oxidative DNA damage (Daly et al., 2007). Therefore, we determined the carbonyl content of the tested bacterial species by inducing oxidative damage with $\mathrm{H}_{2} \mathrm{O}_{2}$ and comparing the content with that of controls (without $\mathrm{H}_{2} \mathrm{O}_{2}$ treatment).

After $\mathrm{H}_{2} \mathrm{O}_{2}$ treatment, the carbonyl content of $D$. maris 7011 was $0.0441 \mathrm{mmol} / \mathrm{mg}$ protein. It was significantly higher $(P<0.001)$ than the control value $\left(0.0272 \mathrm{mmol} / \mathrm{mg}\right.$ protein; without $\mathrm{H}_{2} \mathrm{O}_{2}$ treatment). Hence, it may be concluded that when $D$. maris 7011 is affected by oxidative molecules, the strain does not produce any carotenoids.

After $\mathrm{H}_{2} \mathrm{O}_{2}$ treatment, the carbonyl content of $D$. maris NITD (which produces CX) was $0.0276 \mathrm{mmol} / \mathrm{mg}$ protein. The value obtained $(0.0258 \mathrm{mmol} / \mathrm{mg}$ protein $)$ was not significantly different $(P=0.017)$ from the control value. The results for the protein carbonylation level assay for both normal and $\mathrm{H}_{2} \mathrm{O}_{2}$-treated cells agreed with those of a similar study conducted by Tian et al. (2009). The authors showed that the carbonyl content in a wildtype strain (carotenoid producer) and a mutant strain (non-carotenoid producer) of Deinococcus radiodurans after $\mathrm{H}_{2} \mathrm{O}_{2}$ treatment was 0.0169 and $0.0212 \mathrm{mmol} / \mathrm{mg}$, respectively. This result shows that the intracellular proteins in $D$. maris 7011 were more sensitive to oxidative damage than those of $D$. maris NITD because of a higher $\mathrm{CX}$ production by the latter strain than the former one. Apart from the primary defense proteins such as superoxide dismutases, catalases and glutaredoxin 2 (Tian et al., 2009), CX has recently been shown to be required in protection against protein oxidation, particularly in the stationary phase of growth in Escherichia coli (Nystrom, 2002). In our case, the functional group polarity and orientation of the terminal ring CX probably played a key role as an ROS scavenger (Bera et al., 2017).

Many important proteins, including DNA repair proteins and enzymes involved in cell recovery, might be protected by carotenoids in the cells (Tian et al., 2007). Iron ions released from oxidative-damaged proteins containing iron-sulfur clusters can react with $\mathrm{H}_{2} \mathrm{O}_{2}$ to form the most harmful hydroxyl radical in the Fenton reaction (Tian et al., 2007). In D. maris NITD, the inhibition of protein oxidation by the BCX in vitro was $13.28 \%$ and $30.18 \%$ at 50 and $300 \mu \mathrm{g} / \mathrm{ml}$ concentrations, respectively. Figure 1 shows the inhibition of protein oxidation by different standard carotenoids with respect to BCX. The results showed 12.91, 15.74 and $15.56 \%$ inhibition by standard zeaxanthin, $\beta$-cryptoxanthin and $\beta$-carotene, respectively, at $50 \mu \mathrm{g} / \mathrm{ml}$ concentration. At $100 \mu \mathrm{g} / \mathrm{ml}$, the inhibition of protein oxidation by these three compounds was $27.55,38.41$ and $35.22 \%$, respectively. Hence, $D$. maris NITD might be a good alternative for producing synthetic antioxidants for scavenging ROS, thus preventing protein oxidation. $\beta$-Cryptoxanthin and $\beta$-carotene showed a higher inhibition of protein oxidation because of their multiple functional groups in the terminal ring, which facilitate their high radical scavenging property. Figure 2 shows a correlation between $\mathrm{BCX}$ and a pure standard CX (PCX) and other synthetic antioxidants (i.e. ascorbic acid and BHA) when their concentration varied from 50 to $300 \mu \mathrm{g} / \mathrm{ml}$. The correla- 


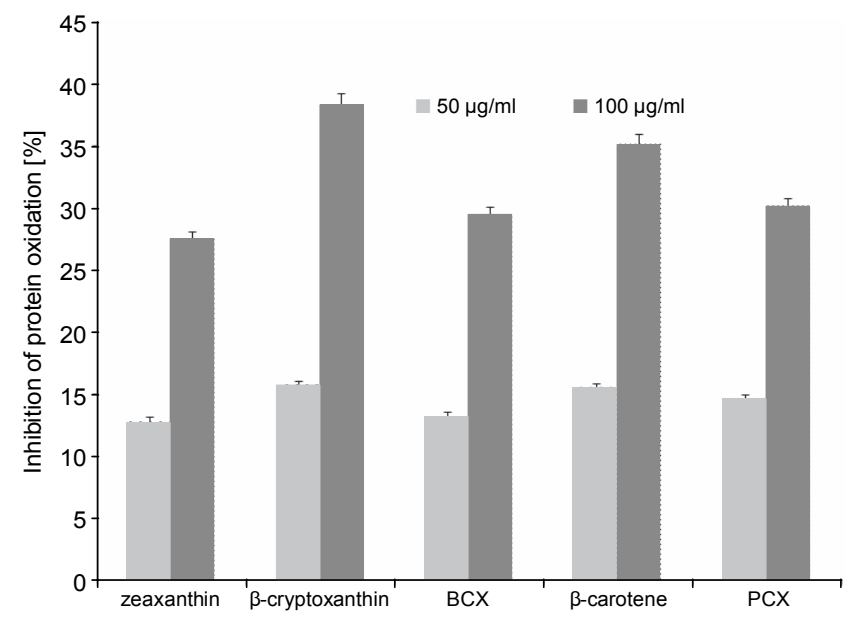

Fig. 1. Inhibition of protein oxidation by different carotenoids

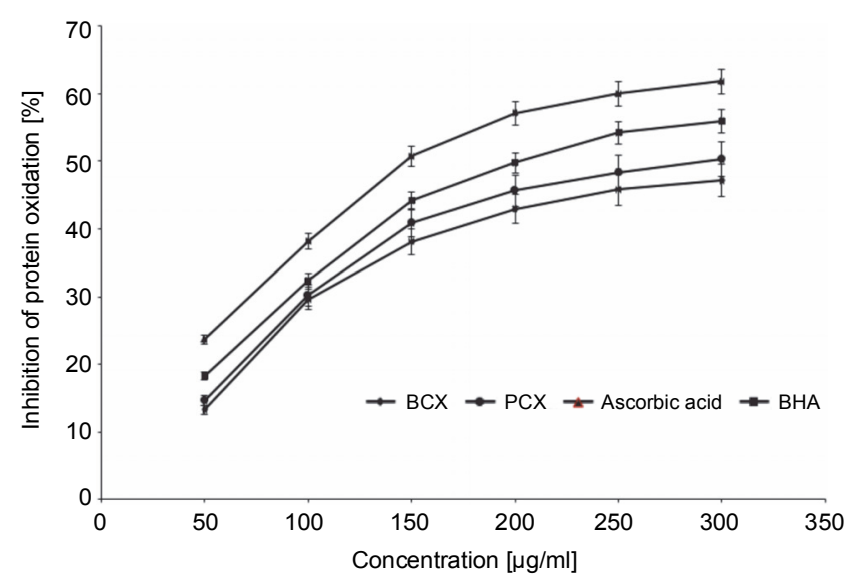

Fig. 2. Typical correlation graph between different antioxidants in terms of protein oxidation in vitro

tion coefficient between BCX-PCX, BCX-ascorbic acid and BCX-BHA was $0.9989,0.9950$ and 0.9943 , respectively. These values indicate that $C X$ from $D$. maris NITD has more functional similarity with the standard CX. On the other hand, the inhibition of protein oxidation by PCX was 14.65 and $50.28 \%$ at 50 and $300 \mu \mathrm{g} / \mathrm{ml}$ concentrations, respectively, which was higher than that extracted from BCX. Ascorbic acid showed highest inhibition of protein damage (23.67 and $61.81 \%$ ) at 50 and $300 \mu \mathrm{g} / \mathrm{ml}$ concentrations, respectively.

\section{Effect of carotenoids from D. maris NITD on lipid peroxidation}

Lipid peroxidation by ROS is believed to be associated with the pathology of many diseases and health conditions (Van der Paal et al., 2016). Thus, the inhibition of lipid peroxidation is considered to be one of the most important indices of antioxidant potential (Van der

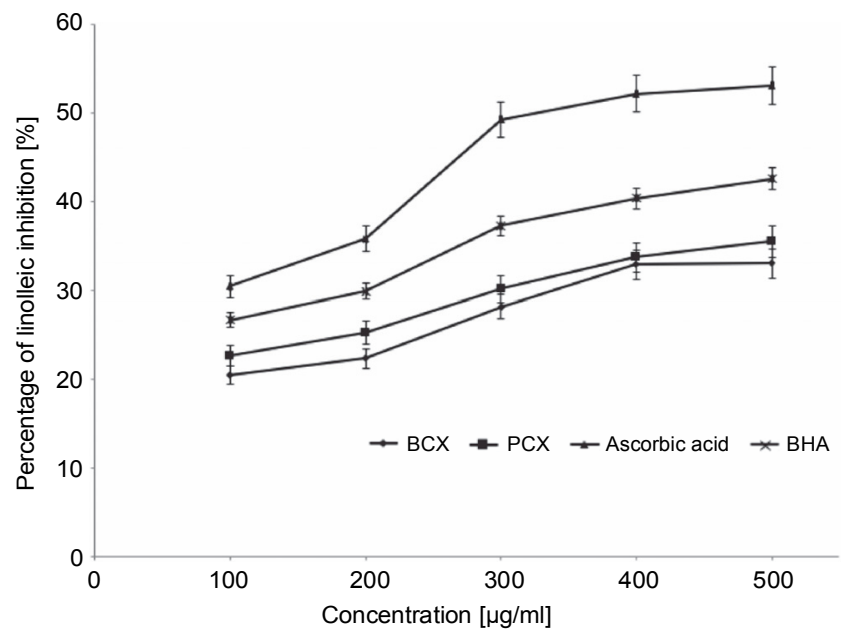

Fig. 3. Linoleic acid inhibition percentage for different antioxidants in vitro

Paal et al., 2016). During lipid peroxidation, different hydroperoxides lead to the transformation of a substrate into by-products such as malondialdehyde (MDA). An increase in the MDA content in the linoleic acid emulsion is an evidence of a continuing oxidation process of the lipids (Gramza-Michałowska and Stachowiak, 2010). Figure 3 shows typical patterns of the linoleic acid inhibition percentage for $\mathrm{BCX}$ and $\mathrm{PCX}$ with varying concentrations from 100 to $500 \mu \mathrm{g} / \mathrm{ml}$. The results revealed that $100 \mu \mathrm{g} / \mathrm{ml} \mathrm{BCX}$ and PCX showed 20.42 and $22.64 \%$ of linoleic acid inhibition, which increased to 33.02 and $35.45 \%$ at $500 \mu \mathrm{g} / \mathrm{ml}$ concentration, respectively. $\mathrm{IC}_{50}$ values were determined to be 932.48 and $905.64 \mu \mathrm{g} / \mathrm{ml}$ for BCX and PCX, respectively. Ascorbic acid and BHA showed low $\mathrm{IC}_{50}$ values at 395.09 and $647.99 \mu \mathrm{g} / \mathrm{ml}$, respectively. Gramza-Michałowska and Stachowiak (2010) showed that carotenoids retard hydroperoxide formation on azo-initiated lipid peroxidation in homogeneous methyl linoleate/AMVN $\left\{2,2^{\prime}\right.$-azobis (2,4-dimethylvaleronitrile)\} systems. The authors found $0.45 \%$ antioxidant activity with $1 \%$ extract of astaxanthin from Phaffia rhodozyma, and they proposed that carotenoids with oxogroups may retard hydroperoxide formation more efficiently than non-oxocarotenoids. The functional group present in the terminal CX may be responsible for the inhibition of linoleic acid peroxidation in vitro.

In this regard, it is worthy to mention that another effective approach to assess MDA formation is TBARS measurement. The reaction requires an acidic environment where two moles of TBA react with one mole of MDA to form a pink product, which is readily extractable 
in organic solvents and gives absorbance at $530-535 \mathrm{~nm}$ (Britton et al., 2009). The reaction is presented below:

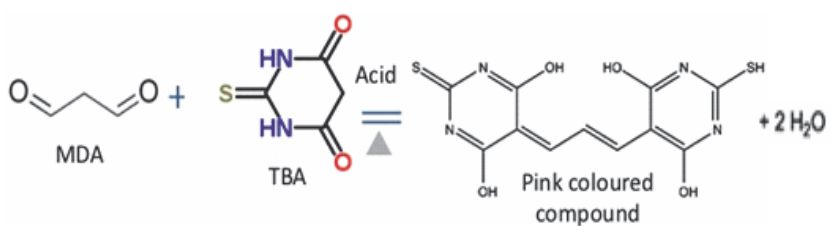

Figure 4 shows percentages of the inhibition of lipid peroxidation by BCX, PCX, ascorbic acid, and BHA at varying concentrations from 100 to $500 \mu \mathrm{g} / \mathrm{ml}$. The result obtained in this model followed similar trends to that noted in the linoleic acid model. At $100 \mu \mathrm{g} / \mathrm{ml}$, the percentage of inhibition of lipid peroxidation by BCX and PCX was 32.43 and $35.21 \%$, whereas at $500 \mu \mathrm{g} / \mathrm{ml}$, the percentage increased to 56.47 and $57.28 \%$, respectively. Ascorbic acid and BHA showed 47.96 and $42.61 \%$ inhibition of lipid peroxidation at $100 \mu \mathrm{g} / \mathrm{ml}$, respectively. A study conducted by Lavy et al. (2005) on Deinococcus radiophilus extract showed an approximately $90 \%$ inhibition in TBARS formation during the lipid peroxidation study. A recent study by Matumoto-Pintro et al. (2017) showed a high lipid peroxidation inhibition by egg powder enriched with lycopene (a red carotenoid). Our experimental results of TBARS in the goat liver model were slightly higher than those obtained in the linoleic acid model study for the same concentrations of carotenoids (Fig. 3 and Fig. 4). This may be due to the apparent presence of fresh and active enzymes such as aspartate transaminase and alanine transaminase in a freshly excised goat liver.

\section{Effect of carotenoids from D. maris NITD on DNA damage protection}

Studies on simple prokaryotic models such as a bacterial system enable to identify risk factors in the form of accumulation of oxidative-damaged proteins. Elevated levels of oxidized proteins may be caused by an increased production of misfolded or malformed polypeptides (Nystrom, 2002). Any damage to regulatory proteins participating in the cellular expression machinery by ROS may lead to a catastrophic degeneration of nucleic acids inside the cells, which eventually induce apoptosis, followed by death of the cells (Milani et al., 2017). Therefore, the protection of DNA by carotenoids may be partial because of the fact that carotenoids prevent protein oxidation. In this experiment, hydroxyl radicals generated from Fenton's reaction caused damage to DNA

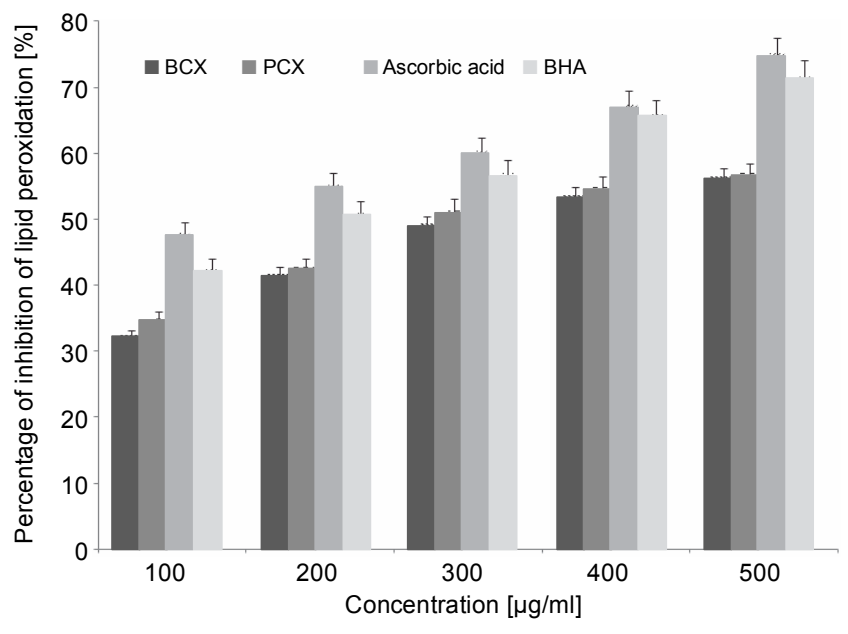

Fig. 4. Inhibition percentage of lipid peroxidation by different antioxidants in vitro

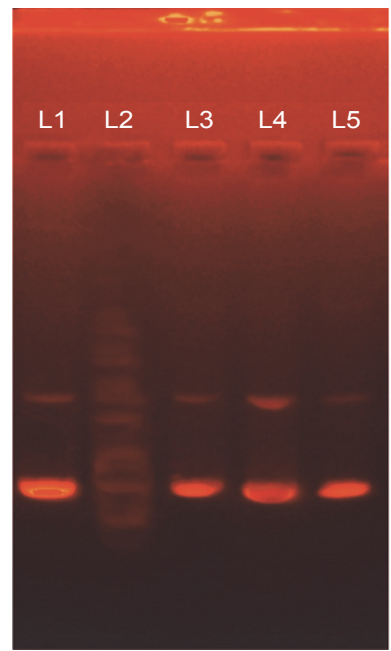

Fig. 5. DNA damage protection study by agarose gel electrophoresis: L1 - only pBR322 DNA, L2 - DNA + fenton's reagent, L3 - DNA + BCX, L4 - DNA + quercetin, L5 - DNA + PCX

(pBR322). In Figure 5, lane 1 shows an intact DNA band, while shows a smear of DNA, indicating the presence of a degraded DNA due to ROS generated by Fenton's reaction. Lanes 3,4 , and 5showed less smeared DNA (observable intactness of pBR322) due to the presence of the antioxidant compounds quercetin, BCX and PCX, respectively. The results of our experiments are in accordance with those of Tian et al. (2007) where the authors investigated the effect of carotenoids (e.g. deinoxanthin) extracted from Deinococcus radiodurans on DNA damage protection. Kumar et al. (2013) also conducted similar experiments and proved that Helicteres isora L. fruit extract was a promising antioxidant to pro- 
tect DNA intactness from ROS generated in Fenton's reaction. The high antioxidant activity of $\mathrm{BCX}$ may be attributed to its distinctive chemical nature with long extended conjugated double bonds and terminal functional group, which eventually provide protection from DNA degeneration by ROS in vitro.

\section{Conclusions}

In summary, the present study revealed that $\mathrm{CX}$ from D. maris NITD may have a significant effect on the inhibition of protein oxidation in vitro. Moreover, non-CXproducing $D$. maris 7011 is more prone to internal damage due to oxidative stress than CX-producing $D$. maris NITD. The study on inhibition of lipid peroxidation also showed protective effect of $\mathrm{CX}$ against lipid peroxidation in both linoleic acid and goat liver models. The DNA damage protection experiment suggested that $\mathrm{CX}$ is more likely to prevent pBR322 DNA damage. Further detailed experiments need to be conducted to investigate the molecular mechanism of protective action of CX in D. maris NITD for its future application as a therapeutic agent.

\section{Acknowledgments}

The experimental work for this manuscript was performed by the author, Surojit Bera, as a part of his PhD thesis at the Department of Biotechnology, National Institute of Technology Durgapur, India, with fellowship support from the 'INSPIRE' Programme [fellowship number IF120552] from the Department of Science and Technology (DST), the Ministry of Science and Technology, the Government of India, New Delhi. Work design, manuscript drafting and correction were performed by Surojit Bera. The author also wishes to express his sincere gratitude to the Department of Biotechnology, National Institute of Technology Durgapur, India, for technical support during the entire study.

\section{References}

Bera S. (2019) Carotenoids: updates on legal statutory and competence for nutraceutical properties. Curr. Res. Nutr. Food Sci. 7(2): 300-319.

Bera S., Dutta D. (2017) Encapsulation and release of a bacterial carotenoid from hydrogel matrix: characterization, $\mathrm{ki}$ netics and antioxidant study. Eng. Life Sci. 17(7): 739-748.

Bera S., Bharadwaj S.V., Chaudhuri S., Dutta D. (2015) Strong antioxidant property of bacterial canthaxanthin obtained by raw coconut water supplementation as an additional nutrient source. [in:] Proceedings of 2015 International Conference on Bio-Medical Engineering and Environmental Technology: 129-136.
Bera S., Chaudhuri S., Dutta D. (2017b) Stability and antioxidant study of bacterial canthaxanthin in aloe-vera model system. Res. J. Pharm. Biol. Chem. Sci. 8(4): 1169-1179.

Bera S., Sharma V.P., Dutta S., Dutta D. (2016) Biological decolorization and detoxification of malachite green from aqueous solution by Dietzia maris NIT-D. J. Taiwan Inst. Chem. Eng. 67: 271-284.

Bradford M.M. (1976) A rapid and sensitive method for the quantitation of microgram quantities of protein utilizing the principle of protein-dye binding. Anal. Biochem. 72(1-2): 248-254.

Britton G., Liaaen-Jensen S., Pfander H. (2009) Carotenoids: Volume 5: Nutrition and Health. Birkhaüser Verlag, Basel, Switzerland: $1-85$.

Costa V., Quintanilha A., Moradas Ferreira P. (2007) Protein oxidation, repair mechanisms and proteolysis in Saccharomyces cerevisiae. IUBMB life. 59(4-5): 293-298.

Daly M.J., Gaidamakova E.K., Matrosova V.Y., Vasilenko A., Zhai M., Leapman R.D., Lai B., Ravel B., Li S.M.W., Kemner K.M., Fredrickson J.K. (2007) Protein oxidation implicated as the primary determinant of bacterial radioresistance. PLoS Biol. 5(4): 769-779.

Gharibzahedi S.M.T., Razavi S.H., Mousavi M. (2014) Potential applications and emerging trends of species of the genus Dietzia: a review. Ann. Microbiol. 64(2): 421-429.

Goswami G., Chakraborty S., Chaudhuri S., Dutta D. (2012) Optimization of process parameters by response surface methodology and kinetic modeling for batch production of canthaxanthin by Dietzia maris NIT-D (accession number: HM151403). Bioprocess. Biosyst. Eng. 35(8): 1375-1388.

Gramza-Michałowska A., Stachowiak B. (2010) The antioxidant potential of carotenoid extract from Phaffia rhodozyma. Acta Sci. Pol. Technol. Aliment. 9(2): 171-188.

Khodaiyan F., Razavi S.H., Emam-Djomeh Z., Mousavi S.M.A., Hejazi M.A. (2007) Effect of culture conditions on canthaxanthin production by Dietzia natronolimnaea HS-1. J. Microbiol. Biotechnol. 17(2): 195-201.

Kumar V., Sharma M., Lemos M., Shriram V. (2013) Efficacy of Helicteres isora L. against free radicals, lipid peroxidation, protein oxidation and DNA damage. J. Pharm. Res. 6(6): 620-625.

Lavy A., Neeman Y., Fuhrman B. (2005) The antioxidative effect of the bacteria Dienococcus radiophilus against $L D L$ lipid peroxidation. Eur. J. Nutr. 44(5): 281-284.

Lingnert H., Vallentin K., Eriksson C.E. (1979) Measurement of anti-oxidative effect in model system. J. Food Process. Preserv. 3(2): 87-103.

Matumoto-Pintro P.T., Murakami A.E., Vital A.C.P., Croge C., da Silva D.F., Ospina-Roja I.C., Guerra A.F.Q.G. (2017) Effects of storage time and temperature on lipid oxidation of egg powders enriched with natural antioxidants. Food Chem. 228: 463-468.

Milani A., Basirnejad M., Shahbazi S., Bolhassani A. (2017) Carotenoids: biochemistry, pharmacology and treatment. Br. J. Pharmacol. 174(11): 1290-1324. 
Mitra R., Dutta D. (2018) Growth profiling, kinetics and substrate utilization of low-cost dairy waste for production of $\beta$-cryptoxanthin by Kocuria marina DAGII. R. Soc. Open Sci. 5(7): 172318.

Mitra R., Samanta A.K., Chaudhuri S., Dutta D. (2016) Impact of carbon source on $\beta$-cryptoxanthin production by Kocuria marina DAGII: a classical approach. Mater Today Proc. 3(10): 3269-3275.

Mitra R., Chaudhuri S., Dutta D. (2017a) Modelling the growth kinetics of Kocuria marina DAGII as a function of single and binary substrate during batch production of $\beta$ cryptoxanthin. Bioprocess. Biosyst. Eng. 40(1): 99-113.

Mitra R., Samanta A.K., Chaudhuri S., Dutta D. (2017b) Effect of selected physico-chemical factors on bacterial $\beta$-cryptoxanthin degradation: stability and kinetic study. J. Food Process. Eng. 40(2): 1-8.

Nystrom T. (2002) Aging in bacteria. Curr. Opin. Microbiol. 5(6): 596-601.

Rajendiran S., Zachariah B., Hamide A. (2012) Increased protein carbonylation and decreased antioxidant status in anemic $H$. pylori infected patients: effect of treatment. Saudi J. Gastroenterol. 18(4): 252-256.

Simon H.U., Haj-Yehia A., Levi-Schaffer F. (2000) Role of reactive oxygen species (ROS) in apoptosis induction. Apoptosis 5(5): 415-418.
Sonar A.K., Mitra R., Dutta, D. (2016) Effect of oxidative stress on Kocuria marina DAGII during $\beta$-cryptoxanthin biosynthesis. Int. J. Biotechnol. Biomed. Sci. 2(1): 93-95.

Tan C., Xue J., Lou X., Abbas S., Guan Y., Feng B., Zhang X., Xia S. (2014) Liposomes as delivery systems for carotenoids: comparative studies of loading ability, storage stability and in vitro release. Food Funct. 5(6): 1232-1240.

Tian B., Sun Z., Shen S., Wang H., Jiao J., Wang L., Hu Y., Hua Y. (2009) Effects of carotenoids from Deinococcus radiodurans on protein oxidation. Lett. Appl. Microbiol. 49(6): 689-694.

Tian B., Xu Z., Sun Z., Lin J., Hua Y. (2007) Evaluation of the antioxidant effects of carotenoids from Deinococcus radiodurans through targeted mutagenesis, chemiluminescence, and DNA damage analyses. Biochim. Biophys. Acta Gen. Subj. 1770(6): 902-911.

Van der Paal J., Neyts E.C., Verlackt C.C., Bogaerts A. (2016) Effect of lipid peroxidation on membrane permeability of cancer and normal cells subjected to oxidative stress. Chem. Sci. 7(1): 489-498.

Venugopalan V., Tripathi S.K., Nahar P., Saradhi P.P., Das R.H., Gautam H.K. (2013) Characterization of canthaxanthin isomers isolated from a new soil Dietzia sp. and their antioxidant activities. J. Microbiol. Biotechnol. 23(2): $237-245$. 